\title{
Crónica de la jurisprudencia del Tribunal Constitucional sobre igualdad (año 2018)
}

\section{Chronicle of the Spanish Constitutional Court case on equality rights (year 2018)}

\author{
RicARdo PEdRo Ron LATAS \\ Profesor Titular de Universidad \\ de Derecho del Trabajo y Seguridad Social \\ Universidade da Coruña \\ Magistrado Suplente \\ Sala de lo Social del TSJ Galicia
}

doi: https://doi.org/10.20318/femeris.2019.4772

Resumen. Este estudio aborda el análisis de las sentencias dictadas en aplicación del principio de igualdad y no discriminación por el Tribunal Constitucional el año 2018. El estudio se centra en el estudio de las sentencias más relevantes en este terreno que ha producido el Tribunal Constitucional en el año 2018.

Palabras clave: Tribunal Constitucional, Principio de igualdad de trato, No discriminación.

Abstract. This study tackle the analysis of judgments dictated in application of the principle of equal treatment and nondiscrimination by the Constitutional Court of Justice of Spain during the year 2018. The article will centre in the study of the most notable sentences in this terrain that has produced the Constitutional Court during the year 2018.

Keywords: Constitutional Court of Justice of Spain, Principle of equal treatment, Nondiscrimination.

El año 2018, en el ámbito de la jurisprudencia dictada en aplicación del principio de igualdad de trato y no discriminación que consagra el artículo 14 de la CE por el Tribunal Constitucional, pueden reseñarse únicamente dos resoluciones.

"ricardo.ron@udc.es 


\section{Sentencia 111/2018 de 17 de octubre. Permisos en supuestos de parto. Duración distinta de los permisos y duraciones según se trate del padre o de la madre}

La primera de esas dos sentencias resulta ser la sentencia número 111/2018, de 17 de octubre. En ella se aborda un tema ya clásico en la jurisprudencia constitucional (y también, como no, en la ordinaria) desde la creación del permiso de paternidad tras la promulgación de la -ya lejana- Ley 40/2007, de 4 de diciembre; norma ésta que, como se sabe, estableció como medida "innovadora para favorecer la conciliación de la vida personal, familiar y laboral" el permiso de paternidad de trece días de duración, ampliable en caso de parto múltiple en dos días más por cada hijo o hija a partir del segundo. Se trataba (y se trata) de un derecho individual y exclusivo del padre, que se reconoce tanto en los supuestos de paternidad biológica como en los de adopción y acogimiento. De igual modo, la norma introdujo como necesaria novedad la creación de la prestación económica por paternidad.

La sentencia que aquí nos ocupa trajo causa de un recurso de amparo promovido por un particular y la asociación "Plataforma por permisos iguales e intransferibles de nacimiento y adopción (PPiiNA)", contra la Sentencia dictada por la Sala de lo Social del Tribunal Superior de Justicia de Madrid el 30 de junio de 2017, que desestimó el recurso de suplicación interpuesto contra la Sentencia de 22 de diciembre de 2016 del Juzgado de lo Social núm. 30 de Madrid, dictada en los autos núm. 278-2016, así como frente a precedentes resoluciones del Instituto Nacional de la Seguridad Social.

La cuestión objeto de la litis traía causa de la solicitud de un padre de equiparación -no hace falta recordar que los permios de maternidad y paternidad, así como sus correspondientes prestaciones presentan diversa duración- y ampliación de la prestación de paternidad con la prestación por maternidad, tanto en lo que se refiere a las condiciones de disfrute como a su duración (16 semanas), con carácter personal e intransferible.

Como fundamento de la pretensión se invocaba el derecho a la igualdad y a no sufrir discriminación (art. $14 \mathrm{CE}$ ), aduciendo, en síntesis, que la decisión administrativa de no equiparar la prestación de paternidad con la prestación por maternidad constituía un acto discriminatorio por razón de sexo, basado en una interpretación literal y formalista de la normativa aplicable contenida en el Estatuto de los Trabajadores y en la Ley General de la Seguridad Social. Se alegaba también que la equiparación de la prestación de paternidad con la de maternidad se conecta con la conciliación de responsabilidades familiares dimanante del principio de protección de la familia (art. 39 CE), y que la equiparación pretendida era una exigencia del derecho europeo, que prevalece sobre la normativa nacional, invocando a tal efecto los arts. 2 y 3 del Tratado de la Unión Europea, los arts. 21 y 23 de la Carta de los Derechos Fundamentales de la Unión Europea , y la Directiva 2006/54/ CE del Parlamento Europeo y del Consejo, de 5 de julio de 2006, relativa a la aplicación del principio de igualdad de oportunidades e igualdad de trato entre hombres y mujeres en asuntos de empleo y ocupación.

Por razones de índole material, el objeto del recurso de amparo se limitó finalmente a la hipotética vulneración aquí del derecho a la igualdad ante la ley y a no sufrir discriminación por razón de sexo (art. $14 \mathrm{CE}$ ). En concreto, lo que se discutió en amparo fue si la 
decisión administrativa (confirmada en vía judicial) de no conceder al padre el derecho a disfrutar la prestación de seguridad social por paternidad tras el nacimiento de su hijo, con la misma duración que la establecida para el permiso por maternidad, supone un trato desigual carente de justificación razonable y proporcionada, que además tendría un impacto negativo sobre la conciliación de la vida familiar y laboral.

Como presupuesto previo de la decisión final, el Tribunal Constitucional no duda (de manera honesta) en reconocer que "existe un prolongado debate social y político sobre la conveniencia de ampliar la duración del permiso por paternidad (y la prestación de la seguridad social correspondiente), incluso hasta su equiparación con el permiso por maternidad", hasta el punto de que: 1) se "encuentra asimismo en tramitación parlamentaria una proposición de ley que pretende la equiparación plena de los permisos de maternidad y paternidad"; y 2) se halla en trámite una reciente propuesta de Directiva del Parlamento Europeo y del Consejo relativa a la conciliación de la vida familiar y la vida profesional de los progenitores y los cuidadores (2017/0085), que pretende introducir el derecho de los padres a acogerse al permiso de paternidad durante un breve período, "que no debe ser inferior a diez días laborables", con ocasión del nacimiento de un hijo (art. 4)”.

Sobre esta base, pues, lo que debía decidir el alto tribunal era si la normativa actual puede considerarse conforme al derecho fundamental garantizado por el art. $14 \mathrm{CE}$, como habían entendido los órganos judiciales intervinientes. La respuesta, sin embargo, peca, a mi entender, de excesiva ortodoxia argumental.

La resolución del problema debía partir, según el Tribunal Constitucional de su doctrina al respecto del principio de igualdad, conforme a la cual el mismo no exige en todos los casos un tratamiento legal igual con abstracción de cualquier elemento diferenciador de relevancia jurídica, de manera que no toda desigualdad de trato normativo respecto a la regulación de una determinada materia supone una infracción del art. $14 \mathrm{CE}$, sino tan solo las que introduzcan una diferencia entre situaciones que puedan considerarse iguales, sin que exista una justificación objetiva y razonable para ello. Sería además necesario, para que fuera constitucionalmente lícita la diferencia de trato, que las consecuencias jurídicas que se deriven de tal distinción sean proporcionadas a la finalidad perseguida, de suerte que se eviten resultados excesivamente gravosos o desmedidos. En consecuencia, aquí el juzgador se limitó a examinar si las situaciones que se llevaban a comparación podían considerarse iguales y, en caso de que así fuera, si la diferente duración de los permisos por maternidad y paternidad (y de las correlativas prestaciones económicas de la seguridad social) que establece la legislación aplicable tienen una justificación objetiva, razonable y proporcionada.

Y siendo así, resulta obvio que no la tienen, de ahí la ausencia de valentía jurídica en la fundamentación del tribunal. Porque, para este en el supuesto de parto ("maternidad biológica"), la "finalidad primordial" que persigue desde siempre el legislador es "la protección de la salud de la mujer trabajadora". 0, dicho de otro modo, el legislador ha juzgado como situación merecedora de protección en materia laboral y por el régimen público de la seguridad social el supuesto de parto, "en el que la suspensión del contrato de trabajo con reserva de puesto de la legislación laboral pretende preservar la salud de la trabajadora embarazada sin detrimento de sus derechos laborales, y la prestación económica por ma- 
ternidad de la seguridad social atiende a sustituir la pérdida de rentas laborales de la mujer trabajadora durante ese periodo de descanso (obligatorio como mínimo en las seis semanas inmediatamente siguientes al parto)". En cambio, el derecho del padre resulta ser un "un derecho individual y exclusivo del padre en el supuesto de parto ..., independiente del disfrute compartido de los periodos de descanso por maternidad regulados en el art. 48.4 LET". De ahí que, según el Tribunal Constitucional, "fácilmente se desprende de lo razonado ... que la finalidad que persigue el legislador en la protección laboral y de seguridad social dispensada en el supuesto de parto es diferente en atención a que se trate de la madre o del padre".

Ninguna diferencia supone por lo tanto el hecho de que "los progenitores deben corresponsabilizarse en el cuidado de los hijos comunes, conforme exige el art. 39.3 CE", por cuanto que "la maternidad, y por tanto el embarazo y el parto, son una realidad biológica diferencial objeto de protección, derivada directamente del art. 39.2 de la Constitución y por tanto las ventajas o excepciones que determine para la mujer no pueden considerarse discriminatorias para el hombre". El hecho diferencial, pues, lo supone las diferentes situaciones subjetivas que quieran traerse a la comparación, al no ser efectivamente homogéneas o equiparables.

En esta ocasión, sin embargo, "debemos descartar que esa diferencia de trato en cuanto a la duración de los permisos y prestaciones incurra en vulneración del principio de igualdad ante la ley ( art. $14 \mathrm{CE}$ ) pues se trata de situaciones diferentes en la consideración de la finalidad tuitiva perseguida por el legislador, por lo que no concurre siquiera un término de comparación adecuado". Y es que, "siendo diferentes las situaciones que se traen a comparación, no puede reputarse como lesiva del derecho a la igualdad ante la ley (art. 14 CE) la diferente duración de los permisos por maternidad o paternidad y de las correspondientes prestaciones de la seguridad social que establece la legislación aplicada en las resoluciones administrativas y judiciales que se impugnan en amparo". La atribución del permiso por maternidad, con la correlativa prestación de la seguridad social, a la mujer trabajadora, con una duración superior a la que se reconoce al padre, no es discriminatoria para el varón, al encontrarnos aquí con "realidades biológicas diferenciadas de obligatoria protección, derivada directamente del art. 39.2 CE, que se refiere a la protección integral de las madres".

\section{Sentencia 3/2018, de 22 de enero. Discriminación por razón de edad y discapaci- dad en materia asistencial}

La segunda de las resoluciones anunciadas resulta ser la STC 3/2018, de 22 de enero, que en esta ocasión se ocupa de una discriminación pluricausal. En esta ocasión se trataba de una persona con necesidades especiales, que tenía la condición legal de discapacitado desde el año 1996, con una minusvalía del 65\%, y la situación dependiente grado I (dependencia moderada) desde 2010. Con posterioridad, la Administración autonómica correspondiente dictó Resolución de "Reconocimiento de la situación de dependencia y determinación del Programa Individual de Atención”, en la que se resolvió lo siguiente: "Primero.- Reconocer la situación de dependencia de A.R.S. en grado II nivel 1. Segundo.- 
Aprobar el Programa Individual de Atención de D./D ${ }^{\circ}$ A.R.S., estableciendo como modalidad de intervención más adecuada para su atención: Servicio de atención residencial para personas mayores. Tercero.- Incorporar a D./D ${ }^{\circ}$ A.R.S., y en tanto no sea posible adjudicarle la plaza pública correspondiente a dicho servicio, el/los siguiente/s servicio/s o prestación transitoria: Prestación económica vinculada a cualquier servicio del catálogo del Sistema para la Autonomía y Atención a la Dependencia debidamente acreditado. El abono de la citada prestación económica se hará efectivo una vez aprobado el gasto. La adjudicación por parte de la Consejería de Asuntos Sociales de una plaza del servicio de atención residencial para personas mayores, y el posterior ingreso en ella será causa de extinción del derecho a disfrutar del servicio o prestación transitoria reconocida. En caso de no ingresar en la plaza, será excluido/a de la lista de acceso única, y podrá continuar con la prestación o servicio transitorio reconocido como modalidad de intervención más adecuada para su atención".

En cumplimiento de lo acordado, la Subdirectora General de Prestaciones y Servicios de la Dependencia, Consejería de Asuntos Sociales de la Comunidad de Madrid, dictó resolución en diciembre de 2012 reconociendo al recurrente en amparo como beneficiario de una prestación económica vinculada al servicio, "en cuantía mensual de 300 euros a partir del 1 de diciembre de 2012, así como 2690,32 euros en concepto de atrasos devengados desde la fecha de efectos (02/03/2012) hasta el 30 de noviembre de 2012". A esta resolución se acompaña un certificado de importes abonados por el beneficiario entre los meses de marzo a noviembre 2012, con un importe mensual de 1.475 euros, excepto agosto (que fueron 737,50 euros).

Contra la primera de dichas resoluciones, se interpuso recurso de alzada en el que se precisaba que la discapacidad intelectual que sufría el aquí recurrente en amparo requería de ayuda para la realización de actividades básicas de su vida diaria, así como ayuda especializada para promover su autonomía, razón por la que se hallaba ingresado en un centro privado especializado en atención de personas con discapacidad; instalaciones y personal especializado del que no dispone una residencia de la tercera edad. Añadía además que "sus problemas intelectuales hacen necesario un tipo de actividades específicas que son las que se programan en las residencias especiales para personas con discapacidad intelectual". Alegaba también en el escrito de alzada, en lo que aquí importa, que la negativa al acceso a una residencia específica para personas con discapacidad, por razón de la edad, "no solo es incongruente con la letra y el espíritu de la ley de dependencia, sino claramente discriminatorio, pues niega a una persona la asistencia que necesita en el centro adecuado por una simple razón de edad, lo que va en contra de la Ley 11/2003 de Servicios Sociales de la Comunidad de Madrid y la Convención Internacional de las Naciones Unidas sobre los derechos de las personas con discapacidad, de 13 de diciembre de 2006".

Así las cosas, la demanda de amparo planteaba dos quejas constitucionales, aunque de ellas sólo nos importa la primera: la vulneración del principio de igualdad y no discriminación del art. 14 CE. Afirma así el recurrente en amparo que las resoluciones de la Comunidad de Madrid (confirmadas en vía judicial) le han privado de una atención individualizada en un centro de asistencia a personas discapacitadas, al excluirle de ello por razón de edad, en aplicación de lo dispuesto en el art. 3 de la Orden 1363/1997, de 24 de junio, de la Conse- 
jería de Sanidad y Asuntos Sociales antes citada. Además, se cuestiona que las resoluciones (administrativas y judiciales) hayan aplicado una limitación por razón de la edad (art. 3 de la Orden 1363/1997), que vulnera el art. 14 CE al hallarse desprovista de una justificación objetiva y razonable y resultar desproporcionada. En suma, la queja se refería a la vulneración del derecho a la no discriminación del apartado segundo del art. 14 CE, ocasionada por la denegación al recurrente del régimen asistencial para personas discapacitadas que solicitaba, al aplicársele una exclusión por razón de edad, cuestionando así la aplicación de una regla de exclusión a los mayores de 60 años que produce una discriminación por razón de la edad (art. 14 CE), carente de justificación y cuya consecuencia es la imposibilidad de acceder al tratamiento médico especializado que requiere su minusvalía psíquica.

Y dicha queja alcanzó el éxito esperado por la parte recurrente, como no podía ser de otro modo. La razón es simple: el art. 14 CE protege la edad y la discapacidad como circunstancias personales, y el canon de control aplicable aquí se define por la STC 126/1997, de 3 de julio: "si el principio de igualdad 'no postula ni como fin ni como medio la paridad y sólo exige la razonabilidad de la diferencia de trato', las prohibiciones de discriminación, en cambio, imponen como fin y generalmente como medio la parificación de trato legal, de manera que sólo pueden ser utilizadas excepcionalmente por el legislador como criterio de diferenciación jurídica [...]. Lo que implica la necesidad de usar en el juicio de legitimidad constitucional un canon mucho más estricto y que implica un mayor rigor respecto a las exigencias materiales de proporcionalidad". En cambio, cuando la discriminación se deba no al tenor de una norma, sino a la interpretación y aplicación que de ella hace el órgano judicial con tal resultado de desigualdad, habrá vulneración del derecho, como explica la STC 69/1991, de 8 de abril: "cuando entre varias presunciones igualmente sostenidas a la luz de la experiencia cotidiana, el Juez acepte una para basar en ella un trato que discrimina al justiciable en razón de una circunstancia personal no contemplada por la norma ni relevante de ningún modo para la finalidad perseguida por ésta, equivale a establecer en la aplicación de la norma una diferencia no objetiva ni razonable, sino arbitraria y lesiva por tanto del derecho a la igualdad ante la Ley".

Por otra parte, la edad como factor de discriminación del art. 14 CE ya fue reconocida en la STC 75/1983, de 3 de agosto: "La edad no es de las circunstancias enunciadas normativamente en el art. 14, pero no ha de verse aquí una intención tipificadora cerrada que excluya cualquiera otra de las precisadas en el texto legal, pues en la fórmula del indicado precepto se alude a cualquier otra condición o circunstancia personal o social, carácter de circunstancia personal que debe predicarse de la edad". Se trata, además, de una doctrina recogida también en el ámbito del Consejo de Europa, ya que el art. 14 del Convenio Europeo de Derechos Humanos recoge el principio de no discriminación por una serie de circunstancias personales que enuncia y en la que no aparece incluida la edad, pero con una cláusula abierta al final ("El goce de los derechos y libertades reconocidos en el presente Convenio ha de ser asegurado sin distinción alguna, especialmente por razones de sexo, raza, color, lengua, religión, opiniones políticas u otras, origen nacional o social, pertenencia a una minoría nacional, fortuna, nacimiento o cualquier otra situación"), donde sí tiene cabida, como ha reconocido la jurisprudencia del Tribunal Europeo de Derechos Humanos. 
Por último, y en lo que respecta al derecho comunitario, en relación con la interpretación y aplicación de instrumentos para la lucha contra la discriminación por razón de la edad, aparece en primer término y para el sector laboral, la Directiva 2000/78/CE del Consejo, de 27 de noviembre de 2000, "relativa al establecimiento de un marco general para la igualdad de trato en el empleo y la ocupación" (arts. 2 y 6), y con alcance general, el art. 21.1 de la Carta de los Derechos Fundamentales de la Unión Europea de 7 de diciembre de 2000, vinculante ex art. 6 del Tratado de la Unión Europea, que prohíbe expresamente toda clase de discriminación y en particular la ejercida, entre otras circunstancias, por razón de la edad.

Por último, bien sabido es, la doctrina del Tribunal Constitucional también ha reconocido que el padecimiento de una discapacidad constituye una circunstancia personal a la que protege el art. 14 CE contra cualquier forma de discriminación. Así, por ejemplo, la STC 269/1994, de 3 de octubre, en relación con la discapacidad física, declaró en su momento que "la discriminación, tal como es prohibida por el art. 14 de la Constitución, impide la adopción de tratamientos globalmente entorpecedores de la igualdad de trato o de oportunidades de ciertos grupos de sujetos, teniendo dicho tratamiento su origen en la concurrencia en aquéllos de una serie de factores diferenciadores que expresamente el legislador considera prohibidos, por vulnerar la dignidad humana. No siendo cerrado el elenco de factores diferenciales enunciado en el art. 14 C.E., es claro que la minusvalía física puede constituir una causa real de discriminación". Además, reconoce el propio Tribunal Constitucional que la aplicación de la cláusula del art. 10.2 CE debe llevar a otorgar especial relevancia a la Convención de la ONU sobre los derechos de las personas con discapacidad, de 13 de diciembre de 2006, donde se protege, en su art. 1 a todos aquellos quienes "tengan deficiencias físicas, mentales, intelectuales o sensoriales a largo plazo que, al interactuar con diversas barreras, puedan impedir su participación plena y efectiva en la sociedad, en igualdad de condiciones con las demás", y proscribe de inmediato en su art. 2 la "discriminación por motivo de discapacidad", ante "cualquier distinción, exclusión o restricción por motivos de discapacidad que tenga el propósito o el efecto de obstaculizar o dejar sin efecto el reconocimiento, goce o ejercicio, en igualdad de condiciones, de todos los derechos humanos y libertades fundamentales en los ámbitos político, económico, social, cultural, civil o de otro tipo. Incluye todas las formas de discriminación, entre ellas, la denegación de ajustes razonables", señalando el art. 5.3 que los Estados partes "adoptarán todas las medidas pertinentes para asegurar la realización de ajustes razonables". Por lo tanto, según el Convenio existe discriminación por razón de la discapacidad tanto si se acredita un propósito de causar perjuicio a la persona por el mero hecho de ser discapacitada, como si se constata que se ha producido un resultado (el "efecto", en palabras del art. 2) debido a la acción de un responsable, que causa la "distinción, exclusión o restricción" de alguno de los derechos de quién es discapacitado, sin que tenga que concurrir la afectación de ninguna otra circunstancia personal.

Sin necesidad de incidir más en la base jurídica de la decisión del Tribunal Constituciones, sí merece ser destacado que la estimación del recurso de amparo, no por obvia, resulta menos trascedente, ya que en esta ocasión se ha excluido de una prestación sanitaria a una persona con necesidades especiales por el mero hecho de haber cumplido una 
determinada edad, y que además no había podido ser beneficiario del sistema de dependencia al que tenía derecho, otorgándole a cambio una plaza en una residencia para personas mayores, sin tratamiento para su discapacidad, y una asignación de 300 euros mensuales (y devolución de las cantidades correspondientes al periodo vencido hasta entonces) hasta tanto no ingresase en ella. Es más, la mencionada decisión se adoptó prescindiendo de toda valoración médica acerca de su estado y de las necesidades de tratamiento especializado, sin tener siquiera en cuenta cuál podía ser el impacto que supondría para las personas residentes en el centro de mayores donde el recurrente obtuviere plaza la convivencia diaria con una persona que, como él, presenta un cuadro de discapacidad psíquica severa crónica.

A todo lo anterior hay que añadir además que la Orden autonómica "por la que se aprueba el procedimiento de tramitación de solicitudes y adjudicación de plazas en los centros de atención a personas con minusvalía, afectadas de deficiencia mental, que integran la red pública de la Comunidad de Madrid", con arreglo a la cual se adjudica plaza en alguno de los centros de los que esta última dispone y gestiona (residenciales, de día, ocupacionales o con fines específicos) para atender a personas con discapacidad psíquica que exige "tener una edad comprendida, en el momento de formalizar la correspondiente solicitud, entre los dieciocho y los sesenta años", no ofrece excepciones "ni modulación alguna", sin contender en "su breve preámbulo, ni en ningún inciso de su articulado, justificación alguna a esta regla de exclusión por edad". A lo que se añade que otra norma de superior rango, la Ley 11/2003, de 27 de marzo, de Servicios Sociales de la Comunidad de Madrid, aunque articula un régimen algo parecido, permite en su art. 20.1 la continuidad de los servicios sociales que venían disfrutando quienes pasen de una etapa a otra (0-18 años; 18-65 años; + 65 años). De este modo, ni la Ley 11/2003 citada, ni la Ley 39/2006, de dependencia, contienen una regla de exclusión por edad, planteando antes bien un modelo flexible que, si bien se vertebra por sectores de edad, no impide la prestación del tratamiento que requiera la persona necesitada por pasar de un grupo a otro.

Por lo tanto, existían normas jurídicas autonómicas de mayor rango y de fecha posterior que podían haber sido aplicadas en su lugar, evitando así la privación del derecho a la asistencia sanitaria debida que aquélla traía consigo. De este modo, la discriminación se manifiesta, en primer término, por razón de la discapacidad, toda vez que el resultado de la aplicación de la norma autonómica ha conllevado la pérdida del derecho a la asistencia médica por discapacidad psíquica. Y que el criterio que fundaba esa norma se identificase con una circunstancia de orden personal como es la edad debe configurar una segunda causa de discriminación que no desplaza, sino que se suma, a la anterior (discriminación múltiple), en cuanto el recurrente no va a tener la atención que necesita, tanto para su salud como para su integración social, frente a quienes en su misma situación de discapacidad sí disponen de dicha asistencia únicamente por no tener 60 años. En este caso, la exigencia de "ajustes razonables" de la Convención de la ONU (que reproduce nuestra Ley General de derechos de las personas con discapacidad y su inclusión social de 2013) pasaba justamente por asegurar la prestación del servicio asistencial adaptado a sus necesidades de discapacidad. 